Tietz: The Effect of Thermomechanical History on the Strain Hardening of Metals. Trans. AIME 180, Metals Tech., Sept., 1948, TP 2445. Discussion, Trans. Jnl. of Metals (May, 1949) 325.

3. Dushman, Dunbar and Huthsteiner: Creep of Metals. Jnl. Appl. Phys. (1944) 15, 108-124.

4. J. H. Holloman and C. Zener: Conditions of Fracture of Steel. Metals Tech. Dec. 1944. TP 1782.

5. J. H. Hollomon and J. D. Lubahn: Plastic Flow of Metals. Phys. Rev. (1946) 70, Nov. 1 and 15, p. 775.

6. J. H. Holloman: The Mechanical Equation of State. Trans. AIME (1947) 171, 535-543; Metals Tech., Sept., 1946, TP 2034.

7. V. J. Kostanetz: Mechanical Properties of Metals and Alloys in Tension at Low Temperatures. Jnl. Tech. Phys. (U.S.S.R.) (1946) 16, No. 5, 515-554.

8. C. W. MacGregor and J. C. Fisher: Tension Tests at Constant True Strain Rates, Jnl. Appl. Mech., Dec. 1945, 12, A217-A227.

9. C. W. MacGregor and J. C. Fisher: A Velocity-Modified Temperature for the Plastic Flow of Metals. Trans. ASME 1946, 68, A11-A16.

10. D. J. McAdam, Jr. and R. W. Mebs: An Investigation of the Tech- nical Cohesive Strength of Metals. Trans. AIME (1945) 162, 474-536.

11. D. J. McAdam, Jr. and R. W. Mebs: The Technical Cohesive Strength and Other Mechanical Properties of Metals at Low Temperatures. Proc. Am. Soc. Test. Materials (1943) 43, 661-703.

12. D. J. McAdam, Jr., R. W. Mebs, and G. W. Geil: The Technical Cohesive Strength of Some Steels and Light Alloys at Low Temperatures. Proc. Am. Soc. Test. Materials (1944) 44, 593-644.

13. D. J. McAdam, Jr.: The Technical Cohesive Strength of Metals in Terms of the Principal Stresses. Trans. AIME (1945) 162, 542-568.

14. D. J. McAdam, Jr., G. W. Geil, and R. W. Mebs: The Effect of Combined Stresses on the Mechanical Properties of Steels between Room Temperature and $-188^{\circ} \mathrm{C}$. Proc. ASTM (1945) 45.

15. D. J. McAdam, Jr., G. W. Geil and R. W. Mebs: Effects of Combined Stresses on the Mechanical Properties of Some Nonferrous Metals. Trans. ASM (1946) 37, 497-536.

16. D. J. McAdam, Jr., G. W. Geil, and R. W. Mebs: Influence of Plastic Deformation, Combined Stresses and Low Temperature on the Breaking Stress of Ferritic Steels.
Trans. AIME (1947) 172. Metals Tech. Aug. 1947, TP 2220.

17. D. J. McAdam, Jr., G. W. Geil and Frances Jane Cromwell: Flow, Fracture and Ductility of Metals. Trans. AIME 175, 306. Metals Tech. Jan. 1948. TP 2296.

18. D. J. McAdam, Jr., G. W. Geil, and W. D. Jenkins: Influence of Strain Aging on the Fracture Stress of Low-carbon Steel. Trans. AIME (1948) 175. Metals Tech. Jan. 1948. TP 2318.

19. D. J. McAdam, Jr., G. W. Geil and F. J. Cromwell: Influence of Low Temperatures on the Mechanical Properties of 18:8 Chromiumnickel Steel. Trans. ASM (1949) 41, 609-645.

20. G. I. Taylor and W. S. Farren: Heat Developed during Plastic Extension of Metals. Proc. Roy. Soc. (1925) A-107, 425-451.

21. G. I. Taylor and H. Quinney: The Latent Energy Remaining in a Metal after Cold Working. Proc. Roy. Soc. (1934) A-143, 307-326.

22. C. Zener and J. H. Holloman: Plastic Flow and Rupture of Metals. Trans. Am. Soc. Metals (1943) 33, 163-215.

23. C. Zener and J. H. Holloman: Problems in Non-elastic Deformation of Metals. Jnl. Appl. Phys. Feb. $1946,17,68-87$.

\title{
The Thermodynamical Treatment of Very Small Solid Solubilities
}

\section{LESTER GUTTMAN*}

The question of whether classical thermodynamics alone imposes any lower limit to solid solubilities was raised during a discussion among various members $\dagger$ of the Institute for the Study of Metals. Although our conclusions are not new, ${ }^{1}$ they may be worth reiterating, since confusion on this subject seems to persist.

In a binary system $(\mathrm{A}, \mathrm{B})$, the conditions for equilibrium, at constant pressure and temperature, between a solid solution and a liquid solution are

$$
\begin{aligned}
& \mu_{A} S=\mu_{A}{ }^{l} \\
& \mu_{B} S=\mu_{B}{ }^{l}
\end{aligned}
$$

Here $\mu$ denotes the chemical potential either of component $A$ or $B$, as shown by the subscripts, and the superscripts $s$ and $l$ refer to the solid and liquid solutions, respectively. These two conditions are just sufficient to determine the compositions of both phases. Suppose, however, that the solid phase is found experimentally not to contain any of component $B$; then we cannot evaluate $\mu_{B}$, which is defined by

$$
\mu_{B} S=\left(\frac{\partial F^{s}}{\partial n_{B}^{s}}\right)_{n A^{s}, P, T}
$$

Here $n_{A} S$ and $n_{B} S$ are the number of mols of $A$ and $B$, respectively, in the solid, whose free energy is $F^{s}$. Eq $1 \mathrm{~b}$ cannot be used, but it is no longer needed: we stated at the outset that the solid has the composition "pure A," and only the liquid composition need now be determined, from Eq la. All the equilibrium properties of the system can be derived from $\mathrm{Eq}$ la rigorously and simply. Hence there is no purely thermodynamic reason to exclude phase diagrams which show precisely zero solid solubility. Marsh ${ }^{2}$ has objected to such diagrams as implying that even the transformation of pure A begins at the eutectic temperature. In any case, the user of the diagram must have a certain minimum knowledge of how to interpret it, and

Technical Note No. 22 E. Manuscript received June 28, 1949.

* Institute for the Study of Metals, Univ. of Chicago, Chicago, III.

$\dagger$ J. W. Stout, L. Meyer, W. Band, T. Rosenqvist, O. J. Kleppa, the writer, and others.

${ }^{1} \mathrm{~W}$. Hume-Rothery: Jnl. Inst. Metals (1926) XXXV, 295-307.

2 J. S. Marsh: Principles of Phase

Diagrams. McGraw-Hill Book Co., N. Y., 1935. pp. 93-4. it would seem simpler to remember the general rule that eutectic temperatures have no significance for pure components, rather than to show, say, by broken lines, on a scale which will often be exaggerated, a hypothetical solidsolubility about which we know only that it is less than a certain amount.

The case of an intermetallic compound in equilibrium with a binary liquid solution does not require a separate treatment since nothing in the foregoing was dependent on the nature of the components. Therefore, thermodynamics alone does not exclude the possibility that (intermetallic) compounds may exist with compositions always precisely those given by their chemical formulas.

With the aid of extra-thermodynamic methods, one may conclude that the solubility of one solid in another is never exactly zero. On the other hand, one would generally expect that the solubility will be small unless the components resemble one another (as do the metals), or form weakly-bound crystals. Therefore, it is useful to know that when there is no direct evidence for solid-solubility, one may neglect it without violating thermodynamic principles. 